\title{
Digital Tools at the Service of Public Administrations
}

\author{
Maria Grazia Cianci \\ Daniele Calisi \\ Sara Colaceci \\ Francesca Paola Mondelli
}

Abstract

Competitions for ideas for architecture have always been sources of stimulus and research, paving the way for innovative projects that have also guaranteed an economic flow and a naturally consequent social response.

The municipality of Rome, years ago, was the architect of a campaign of this type: the Cento Piazze project included, for the first time, a number of competitions and projects that had never been addressed by a national and international administration.

Our intervention aims to reflect on how and to what extent the Public Administration can now benefit from new technologies and digital tools for the analysis and survey of architecture and public space. These innovations, in fact, now make it possible to provide design with a valid help in the preparation of competitions that increasingly concern urban regeneration at an international level.

Keywords

public administration, survey, cento piazze, heritage digitization, planning.

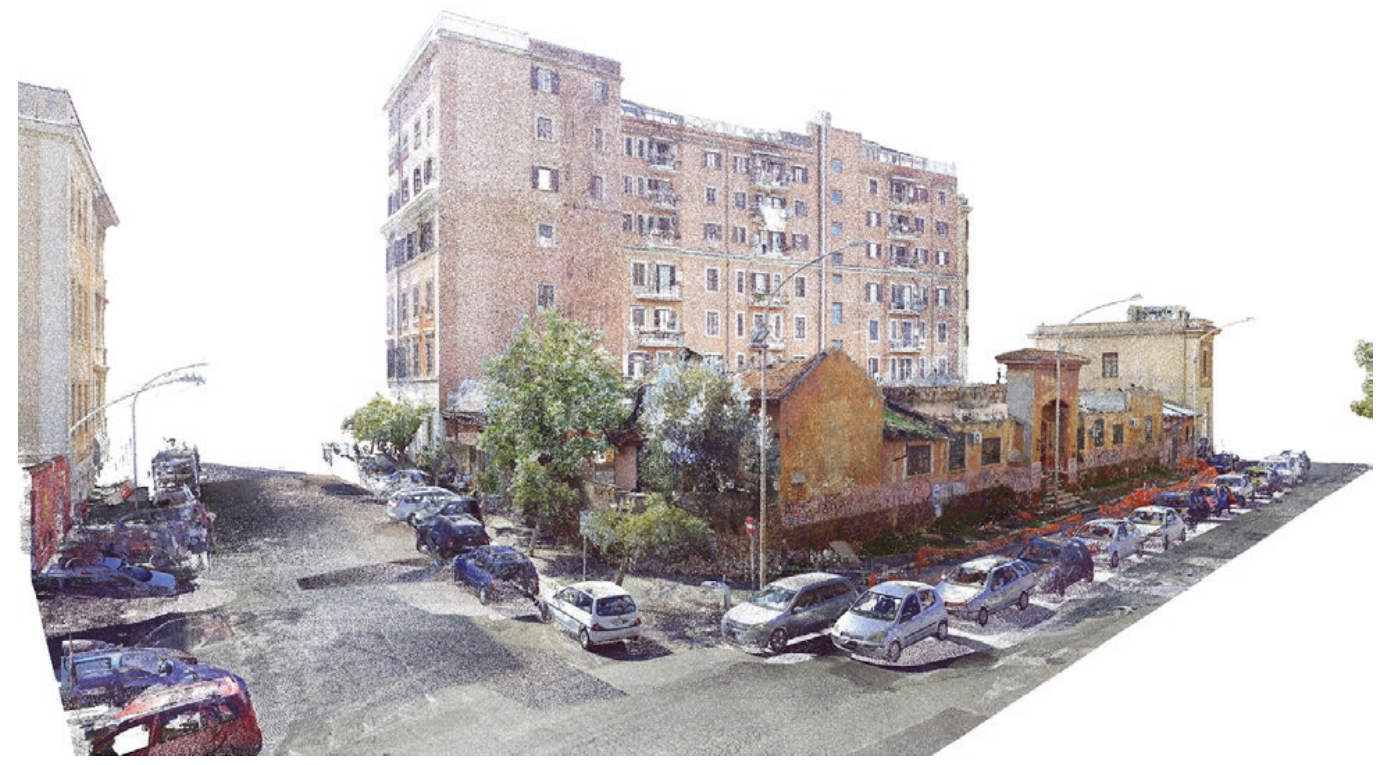




\section{The Centopiazze Program}

In 1996, the Centopiazze program in Rome launched the national competition The neighborhood squares, through which young professionals were invited to deal with the design of 19 open spaces in Rome. Centopiazze was a unique urban redevelopment program of its kind in Rome, through which it was intended to deal with the issue of public space extensively throughout the territory, from the center to the periphery. With the council led by the Mayor Francesco Rutelli, and on the proposal of Prof. Arch. Francesco Ghio, a special program coordination office was set up in the Mayor's Cabinet. Over the course of about a decade, around I 80 public spaces in the city have been transformed, redeveloped or built from scratch.

The Neighborhood squares competition was the first action through which the Centopiazze program was launched. It is very interesting, to date, to look at the competition dossier precisely in order to compare the ways in which, 25 years ago, the areas of intervention were presented with respect to today. The graphic and technical documentation present in the competition dossier reflected the possibilities and means of the time: first of all, a technical plan of the intervention area, with the area within the key-plan of the city of Rome; a brief description of the area with an indication of the functions to be established, location, morphological characteristics of the area, road system, green system, urban context, historical analysis, urban destinations (with reference to the PRG in force in 1996) and the further planned projects in that area; some exemplary axonometric diagrams through which the different lots involved in the competition were compared, drawn with wire; finally, in the most fortunate cases, an aerial photo of the area and some photographs of the site.

\section{Reinventing Cities. Historical-Documentary Research and Surveys}

Today, after more than 20 years, the city of Rome confronted again with the theme of urban regeneration and does so through the Reinventing Cities international competition, A global competition for innovative, resilient and zero-emission urban projects. 12 cities on 4 continents have so far taken part in the competition.

Among these, Rome participates with 4 different areas that will be subject to redevelopment: Ex Mira Lanza in the Ostiense-Marconi area; Ex-Filanda in the San Giovanni area, close to the Aurelian walls; Ex Mercato di Torre Spaccata, Vertunni, in Torre Spaccata area, on the eastern outskirts of the city; and finally the area of the Roma Tuscolana station.

The municipality of Rome has decided to entrust the preparation of historical and analysis documents and the survey of the three areas currently subject to competition as an external assignment. The Roma Tre architecture department was awarded the assignment with the scientific responsibility of Professor Maria Grazia Cianci, thus starting the historical documentary research. For the realization of the three competition dossiers for Ex Filanda, Ex Mercato di Torre Spaccata and Ex Mira Lanza, the working group then dealt with the historical archival research and the elaboration of the integrated survey model, and also with the writing of the texts and graphic design. The dossiers open with a timeline that traces the main stages and transformations of each building, and a chronology drawn up in a discursive, more in-depth and explanatory form. The first two chapters of each issue concern the urban setting of the project sites, and an analysis of the main historical cartography for understanding the territorial and urban context, described and reasoned through the accompanying text. The maps were chosen and placed side by side, suggesting a critical comparison between the different drawings, as in the case of the study of the area where the Ex-Filanda building stands. The topography of the area, leaning against the Aurelian Walls, is compared in the two maps of Du Perac and Bufalini: the first, perspective, shows the lay of the land beyond the walls, in contrast with the dense urban intramural fabric; the second, more technical and zenith, clarifies the territorial conformation with the vallis celimontana in which we see the acquae vocatur marianae flow, the so-called Marrana di San Giovanni.

The dossiers contain all the graphic archive documentation that resulted from the historical research: drawings, projects, surveys, contracts, and historical photographs that are significant for the exhaustive description of each building, tracing the history of each of its transformation. Many sources and archives were consulted, including the Capitoline Historical Archives, the Archives of the Conservatory of Heritage of the Municipality of Rome, the Archives of the Istituto Luce, the Central State Archives. 
Fig. I. Ex Mercato di Torre Spaccata, side elevation: overlaying of the original project drawing on the orthophotoplan from point cloud.
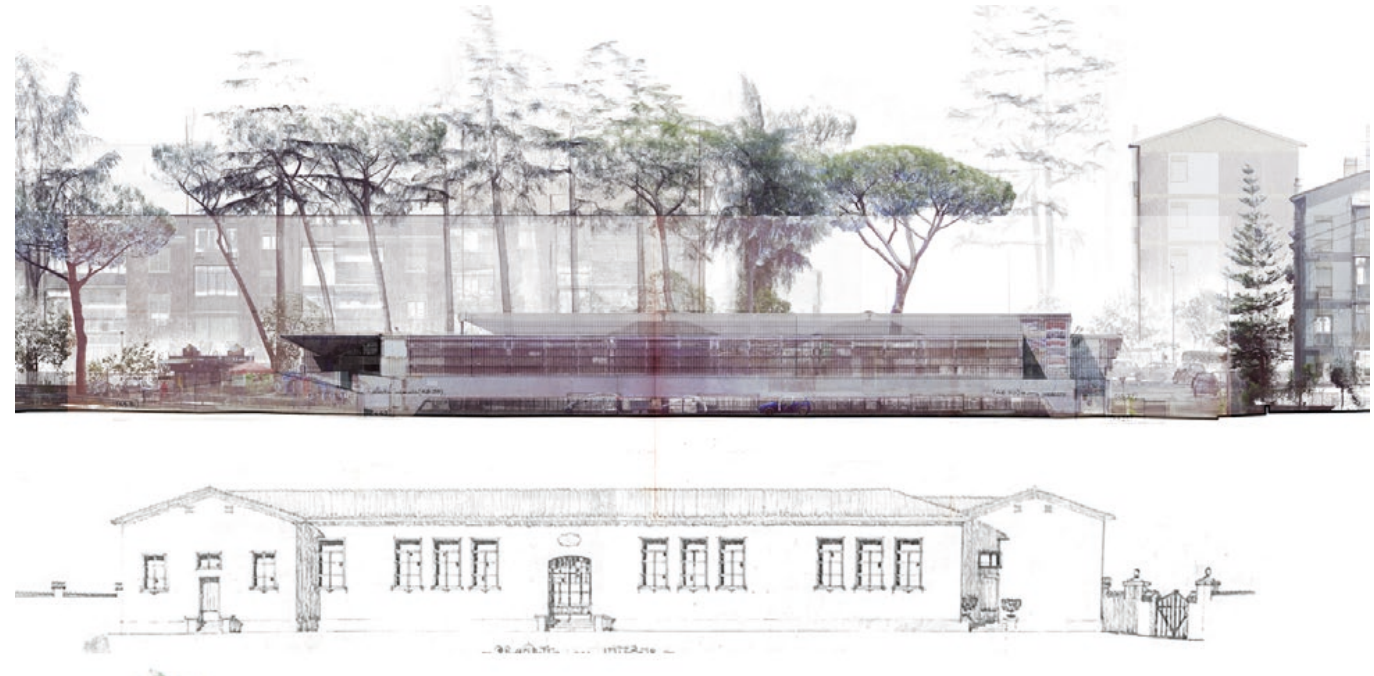

Since these are archival documents that are also very dated, each drawing has been the subject of a careful cleaning and graphic post-production which has been aimed at making the original signs as legible and clear as in the case of the projects attached to the tender specifications for the construction of the pavilion of the Ex Filanda in the Castrense valley: original documents from 1920 preserved in the contract fund of the Capitoline Historical Archive. Based on the results produced by archival research, the various types of documents were presented within the files in order to offer critical and reasoned insights, as in the case of historical photos. In the case of the Ex Mercato di Torre Spaccata, for example, the current state of the building was described through historical photographs resulting from archival research, highlighting the transformations that have taken place over time.

The laser scanner survey represented a separate part of the assignment, as the processing of the point cloud of each of the areas was requested. To obtain it, it was necessary to integrate two instruments: laser scanner and drone. The two point clouds obtained were geo-referenced and superimposed.

It was decided to present the original technical drawings of the project by offering a critical reading, comparing them with the contemporary technical data represented by the orthophotoplanes that resulted from the processing of the point cloud obtained by laser scanner and drone. In this comparison made on the façade of the Ex-Mercato on via Settimio de Vico, for example, we observe the homogeneous character of the external walls characterized by the stepped profile that follows the profile of the internally arranged 'mushrooms'. The comparison between the orthophoto and the relief drawing of the 1980s shows the perimeter closure above the market boundary wall.

Even in the case of the former spinning mill, the same method of analysis was applied: the orthophoto of the elevation on the internal courtyard, for example, was compared with the original project drawing, highlighting the changes that had taken place. It is possible to note, in fact, the construction dating back to 1965 of the accessory bodies that lean against the facade, built once the building was managed by the Servizio Giardini of Rome, and which still houses the offices. In this sense we intended to give scientific value to the work: not a collection of documents, but an integrated re-reading and re-elaboration through modern instruments and their conscious use (fig. I).

Another important fact, in the case of the Ex Filanda, concerns the historical reconstruction that was offered through typological analogy. In fact, this building, built in 1920-1921 by the Municipal Administration with funds from the Roman Committee of Civil Organization for the educational, moral and sanitary assistance of minors living in degraded situations (later known as (fantiae Salus), it was not possible to find specific archival photographic documentation. However, since this is one of the three Infantiae Salus pavilions built in Rome in the 1920s, it was considered useful to refer to and insert in the file the documentation relating to the other two buildings: that of Trastevere and that of Testaccio. 


\section{The Digitization of Archival Documentation and Built Heritage}

One of the main problems that public administrations in Italy are facing is the digitization of the entire archival apparatus, not only linked to bureaucratic aspects, but above all land registry and concessions and licenses. Considering that the European directives require the use of BIM in public procurement (from 2025 also for minimum contracts of $€ 100,000$ ), the administrations are already in strong delay in the digitization of the built heritage which is part of the future programmatic planning of the master plans. The three case studies object of the Reinventing Cities campaign have for years (or decades) been strategic sites for the municipality of Rome, the subject of the study of projects for urban redevelopment and regeneration and subject to a succession of events that have greatly entangled the bureaucratic skein made up of restrictions, prohibitions and permits.

In this background, the urgency required by the call for the execution of the three surveys with laser scanner technology to be provided to the participants is no coincidence. This concern has necessarily imposed a rational and programmatic planning of the survey campaign, taking into account the potential of the tools and the due overlap from two reciprocal laser scanning stations. At the same time, the authorizations were requested for drone flights that were necessary for the photographic campaign and the creation of the discrete $3 \mathrm{~d}$ model in SFM of the roofs (absent in the ground positions).

The point clouds, with a detail of a point every $\pm 1 \mathrm{~mm}$, were mutually aligned in ReCap and subsequently georeferenced, as specifically requested by the PA, thanks to the markers positioned at ground level and for which GPS data has been recorded. The point cloud created for each project site does not, however, exhaust all the drawings needs of a design team. In fact, although it allows the navigability of the site digitally, its interrogation on the formal and dimensional aspects or the perception of the neighboring context, the point cloud must be imported into the CAD environment to provide two-dimensional drawings in orthogonal projections through its management with cutting plans and the redrawing of plans, elevations and sections. This operation is essential to provide the basic iconographic apparatus for the canonical drafting of an architectural project (fig. 2).

Not all PAs or even architectural firms know how to manage point clouds whose management, reading and interpretation requires experience first of all in the science of drawing, of its discretized representation, in different scales, of reality, be it real or virtual. In addition, knowledge, however technical, of the appropriate software is needed to obtain the desired results. The research group engaged in the work of historical research, survey and representation of the competition sites, had to produce plans, elevations and architectural sections, as well as orthophotoplanes useful for understanding the state of decay of the places. Furthermore, the parametric three-dimensional model was created, starting from the point clouds, from two-dimensional CAD and having a constant control with archival documentation, in regard and verification of all design phases.

The work carried out, in record time, was certainly a first positive experience for the Municipality of Rome, a springboard that highlighted many issues of significant importance, first and foremost the need for a digital database of the architectural heritage that allow to accelerate the bureaucratic and planning processes of public procurement.

\section{Conclusions}

While it was once the practice to provide two-dimensional CAD, today technology has allowed administrations to add a third dimension and present instrumental surveys performed with laser scanners and photo-modeling carried out with the flight of a drone as basic material. The point cloud thus obtained will be the three-dimensional basis for design studies, inserting two non-negligible factors into the process. First of all, the now inevitable need to survey, survey and catalog the archaeological, historical and contemporary architectural heritage through tools that are not usual for public administrations and consequently the need to make use of professional technicians in the sector.

In our opinion, moreover, the digital processing of the surveys required by the PA as basic documentation of the insolvency procedures, can represent an intermediate phase towards what could become a real virtualization of the inspection and survey by the designers. The 
translation of the point cloud and the three-dimensional model into an augmented reality experience could pave the way towards the possibility, for professionals from all over the world, to experience the architectures and urban spaces that are the subject of the competition, without the need to visit the project site directly. Following the limitation of the movements that we are experiencing due to the pandemic, in fact, the importance that digital can have in providing information in real time from any and all parts of the world has been highlighted. Just in the last year, the need for digital adaptation has been strongly felt in many different sectors and research has found new life for projects that were once perhaps only on a hypothetical basis, but which today are starting to have concrete foundations.

One can think of the ever wider opening of digital archives of artistic works or archival documentation, the concrete creation of apps and navigation sites by museums, the possibility of being able to walk and interact within the virtual museum space, thanks to virtual reality, perhaps in an even more intimate and intense way than analogue reality.

In this sense, starting from the experience of digital relief and restitution developed within the Reinventing Cities competition, our reflection invites us to make augmented reality an unprecedented opportunity to expand borders and shorten distances in order to gain knowledge, study and transformation of places, even the most distant ones.

Point cloud or 3D NURBS model, linked by a close relationship of geometric dimensional dependence of the second with the first, are both navigable and interrogable digital environments, but they do not allow us to have the immersive perception of three-dimensional space as we would have in the real site. Although the first step taken with the Reinventing Cities experience is a huge step towards the digitization of the historical-architectural heritage, it is desirable that public administrations also proceed towards Virtual Reality, through the inclusion of digitized models in platforms such as Unreal Engine or RevitVR, to ensure immersive design for engineering and architecture firms from all over the world.

The question raises many other questions that research will have to answer over time: which 3D model will be most useful to navigate? How to make the perceptual and sensory aspects as real as possible for a more conscious design? How to solve the problems associated with all kinds of 3D? The point cloud, although dense, is not material and by approaching the architectures, the points and distances between them are identified, allowing a chromatic perception but not of the material. The NURBS model, derived from the cloud, through the still inevitable passage of $2 d$ interpretation on $\mathrm{CAD}$, is not texturized, and therefore, although making the perception spatial and concrete, it does not give us back the chromatic aspects. A mathematical mesh model that can derive from the point cloud, can only partially solve the problems related to perceptual aspects, but the historically treated issues of the discretization of the points and the inevitable loss of detail, especially of the ornamental apparatus, remain. It is necessary that, over time, the public administration aligns itself with the aspects of communication and representation that begin to be typical of museums and archives, realizing that its historical - building heritage (of all eras) is in fact an asset which must be shared in the appropriate manner and for different types of users.

\section{References}

Camagni Flavia, Colaceci Sara, Russo Michele (2019). Reverse modeling of cultural heritage: pipeline and bottlenecks. In International Archives of the Photogrammetry, Remote Sensing and Spatial Information Sciences, XLII-2MW9, pp. 197-204, 10.5 194/isprs-archives-
XLII-2-W9-197-2019.

Capozzi Maria (1926). I Padiglioni Infantiae Salus. Roma: Unione Arti Grafiche Abruzzesi.

Cianci Maria Grazia (20 19). Il Programma "Centopiazze per Roma”. Strategie di riqualificazione dello spazio pubblico romano. Roma: Palombi Editore.

Cianci Maria Grazia, Calisi Daniele, Mondelli Francesca Paola (2020). The Historical and Cultural Memory of the Aurelian Walls: The Archaeological Survey from Ancient Maps to Contemporary Techniques. In Agustín-Hernández L., Vallespín Muniesa A., Fernández-Morales A. (eds .). Graphical Heritage. EGA 2020. Cham: Springer, pp. 605-6I 8.

Cianci Maria Grazia, Calisi Daniele (2018). Draw and survey as a gesture for knowledge. Archaeological and orographic stratifications in Piazza San Luca and Martina in Rome. In Rossella Salerno (ed.). Rappresentazione/materiale/immateriale. Atti

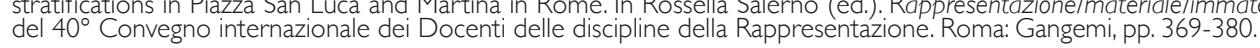

Storelli Franco, Currà Edoardo (2003). II quartiere di Torre Spaccata a Roma ( 1955-63). In Capomolla Rinaldo,Vittorìni Rosalia (eds.). L'architettura INA Casa (1949-1963). Aspetti e problemi di conservazione e recupero. Roma: Gangemi.

\section{Authors}

Maria Grazia Cianci, Dept. of Architecture, University of Roma Tre, mariagrazia.cianci@uniroma3.it

Daniele Calisi, Dept. of Architecture, University of Roma Tre, daniele.calisi@uniroma3.it

Sara Colaceci, Dept. of History, Representation and Restoration of Architecture, Sapienza University of Rome, sara.colaceci@uniroma I.it Francesca Paola Mondelli, Dept.of Architecture, University of Roma Tre, francescapaola.mondelli@uniroma3.it 
